ISSN: 2354 - 1431

http://tckh.daihoctantrao.edu.vn/

\title{
Mẫu người nữ đoan chính trong Truyền kỳ mạn lục của Nguyễn Dũ
}

\author{
KimKi Hyun ${ }^{a}$ \\ ${ }^{a}$ Học viện Khoa họ - Xã hội
}

\section{Article info}

Recieved:

28/572017

Accepted:

03/8/2017

\section{Keywords:}

Truyen ky man luc; Nguyen Du; traditional women;

story of traditional woman in Khoai Chau,

story of traditional woman in

Nam Xuong.

\begin{abstract}
In Truyen ky man luc, Nguyen Dũ has spent 11/20 stories about women, Including 08/11 stories, the woman is the protagonist, the center of the work. From the standard reference system of Confucian ethics and traditional culture of the nation, we realize that there are only two cases: Nhi Khanh (in the Story of traditional woman in Khoai Chau) and Vu Thi Thiet (in the Story of traditional woman in Nam Xuong) meets all the standard criteria of the main ladies. The essay will focus on these two characters, from which to come up with an account of the attitudes and messages of the writer's thought about this women
\end{abstract}

\section{1. Đặt vấn đề}

Dường như ở bất kỳ thời đại nào và ở bất cứ không gian văn hóa nào, người phụ nữ vốn luôn bị đối xử bất công. Bởi lẽ đó mà làn sóng đòi lại quyền bình đẳng cho giới nữ mới xuất hiện, rồi bùng phát và lan tỏa sức ảnh hưởng của nó đến nhiều quốc gia trên thế giới. Các nhà xã hội học đã từng lấy trình độ giải phóng phụ nữ làm thước đo sự tiến bộ của cũng như sự văn minh của một xã hội. Người phụ nữ, theo đó mà cũng từ lâu đã trở thành đề tài, chủ đề, nguồn cảm hứng bất tận trong nghệ thuật nói chung, trong văn học nói riêng. Truyền kỳ mạn luc của Nguyễn Dữ ra đời vào khoảng thế kỷ XVI đã, không những đánh dấu sự phát triển vượt bậc của thể loại mà còn khẳng định tên tuổi của ông như là một trong những nhà nhân đạo chủ nghĩa tiêu biểu của văn học trung đại Việt Nam. Góp phần vào sự thành công đó không thể không nhắc đến chủ đề người phụ nữ trong tập truyện. Với số lượng 11/20 truyện viết về phụ nữ, trong đó có đến 8/11 truyện người phụ nữ là nhân vật chính, trung tâm của tác phẩm, nhà văn đã dành những tình cảm, sự trân trọng thỏa đáng với một nửa thế giới. Trong một bài viết khác, chúng tôi đã bàn về mẫu người phụ nữ phi truyền thống, bài này chúng tôi tập trung bàn về mẫu người nữ truyền thống theo những quy định chuẩn mực của đạo đức Nho giáo. Theo khảo sát của chúng tôi, chỉ có hai nhân vật vinh dự được xếp vào mẫu này: Nàng Nhị Khanh và nàng
Vũ Thị Thiết. Chúng tôi gọi họ là mẫu người nũ đoan chính như một cách suy tôn vẻ đẹp phẩm chất và tâm hồn vượt thời đại của hai con người này.

\section{Nội dung nghiên cứu}

\subsection{Từ những quy định mang tính nghĩa vụ đối với người nữ}

Đối với người phụ nữ, Nho giáo truyền thống có những quy định rất khắt khe, tất nhiên những quy định ấy không phải không có những điểm khả thủ của nó đối với đương thời cũng như hiện nay. Chúng ta có thể cổ súy cho sự giải phóng phụ nữ hay tham gia vào các phong trào đấu tranh đòi bình đẳng, bình quyền cho giới song như một lẽ rất tự nhiên, một số vai trò, chức phận của mỗi giới khó có thể hoán đổi. Trong suy nghĩ của chúng tôi, chỉ cần để cho người nữ được sống, làm việc và hưởng thụ đúng với những gì họ cống hiến đã là một sự bình đẳng đáng trân trọng. Và thực tế đã chỉ ra rằng, dường như không phải nam mà chính là nữ mới là nhân tố góp phần quan trọng trong việc "duy trì một trật tự tương đối" cho mọi "tổ chức" từ nhỏ đến lớn như triều đại hay quốc gia. Vì lẽ như vậy, một khi nhận thức cũng như trình độ phát triển của xã hội còn hạn chế thì để duy trì một "trật tự” như thế, các nhà quản lý buộc phải nương vào các lý thuyết tôn giáo. Trong trường hợp của xã hội phương Đông nói chung, Việt Nam nói riêng thời trung đại, sự lựa chọn của chính thể ở đây là Nho giáo.

Nho giáo đã có một hệ thống quy định mang tính chặt chẽ, khắt khe đối với nhiều lĩnh vực của xã hội, trong đó 
có những yêu cầu cả đối với người nam và người nữ. Sự khác nhau căn bản trong quy định cho hai giới chính là ở chỗ, nếu những quy định với nam chủ yếu là hướng đến việc tạo dựng danh nghiệp, tham gia vào quản lý, tổ chức gia đình, bộ máy chính thể thì với người nữ chủ yếu chỉ tập trung vào việc khắc kỷ, phục lễ, rèn luyện cá nhân để xây dựng gia đình, tạo cơ sở hỗ trợ cho sự thành danh của người chồng chứ không phải cho mình. Theo đó, những điểm chính trong quy định với người nữ bao gồm trong hai mệnh đề tương hỗ là Tam tòng và Tứ đức. Tam tòng nghĩa là có ba đối tượng người nữ nhất nhất phải theo,

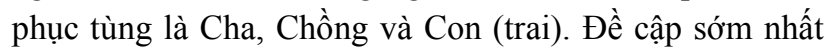
về Tam tòng có thể là sách "Lễ ký". Trong thiên "Giao đăc sinh” có chép: “婦人, 從人者也; 幼從父兄，嫁從夫， 夫死從子”(Nghĩa là: Phụ nữ là phải theo người, lúc nhỏ theo cha anh, lấy chồng thì theo chồng, chồng chết thì theo con). Còn Tứ đức bao gồm: 1) 婦功 (Phụ công): Việc nữ công, gia chánh phải khéo léo. Tuy nhiên các nghề với phụ nữ ngày xưa chủ yếu chỉ là may, vá, thêu, dệt, bếp núc, buôn bán, với người phụ nữ giỏi thì có thêm cầm kỳ thi họa; 2) 婦容 (Phụ dung ): dáng người đàn bà phải hòa nhã, gọn gàng, biết tôn trọng hình thức bản thân; 3) 婦言 (Phụ ngôn): lời ăn tiếng nói khoan thai, dịu dàng, mềm mỏng và 4) 婦行 (Phụ hạnh): Tính nết hiền thảo, trong nhà thì nết na, kính trên nhường dưới, chiều chồng thương con, ăn ở tốt với anh em họ nhà chồng, ra ngoài thì nhu mì chín chắn, không hợm hĩnh hay cay nghiệt...

Trên đây là những điểm cơ bản của thuyết Tam tòng, Tứ đức được coi là những quy định khá khắt khe với người nữ. Sự ảnh hưởng của nó đối với xã hội vừa có những phương diện tiêu cực song vừa có những phương diện tích cực. Trong quá trình phát triển của lịch sử, nhiều khi những quy định này đã bị lợi dụng khiến cho người nữ bị đẩy vào những hoàn cảnh bi kịch. Song ở những điểm khả thủ, chúng tôi cho rằng, nếu vận dụng nó một cách linh hoạt thì thuyết Tam tòng, Tứ đức đã có giá trị tích cực trong việc giáo dục cho người phụ nữ ý tôn trọng kỷ cương, nền nếp gia đình để góp phần ổn định trật tự xã hội, giúp cho giá trị của người phụ nữ được nâng cao, không phân biệt đẳng cấp, địa vị, giàu nghèo. Điều đó cũng sẽ góp phần tạo nên những phẩm chất đạo đức truyền thống quý báu của người phụ nữ Việt Nam là sự nhẫn nại, hy sinh, tần tảo, chịu thương chịu khó; thuỷ chung son sắt, hết lòng vì chồng vì con; vị tha, nhân hậu, giản dị, trọng nghĩa trọng tình; hiếu thảo; hy sinh lợi ích cá nhân vì lợi ích gia đình, dòng tộc... Cũng đồng thời, điều đó còn góp phần răn dạy cho người phụ nữ hoàn thiện cá nhân theo các đức công dung ngôn hạnh đáp ứng yêu cầu phát triển của xã hội hiện đại và hội nhập. Người nữ hoàn toàn có thể không chỉ đảm đang công việc gia đình mà còn tham gia vào công việc xã hội, góp phần vào sự phát triển, tiến bộ của xã hội. Và điểm lý thú là ở chố, nếu trong xã hội cũ, người phụ nữ một mực thủy chung chấp nhất vẫn có thể có bi kịch như thường thì trong xã hội hiện đại ngày nay, trước khi đòi hỏi quyền bình đẳng, người phụ nữ hãy thử soi mình vào những quy định trên kia để xem mình đã được mấy phần. Duy trì và thúc đẩy được ý thức tự kiểm điểm đó, hẳn chăng sẽ góp phần cải thiện, xây dựng hình ảnh tốt đẹp về người nữ khiến cho giới nam cũng như xã hội mặc nhiên thừa nhận và trân trọng.

\section{2. ... đến cuộc đời và số phận của những người nữ đoan chính điển hình}

\subsubsection{Nhân vật Nhị Khanh trong "Chuyện người nghĩa phụ ở Khoái Châu”}

Nàng Nhị Khanh là con gái của Từ Đạt ở Khoái Châu. Ông Đạt có lên làm quan tại thành Đông Quan, thuê nhà ở cạnh cầu Đồng Xuân, rồi kết giao với nhà quan Thiêm thư Phùng Lập Ngôn, mặc dù tính khí và phẩm chất của hai ông khác nhau. Nhân chuyện hứa gả mà sau đó con trai của Phùng mỗ là Trọng Quỳ đã kết duyên với nàng Nhị Khanh. Về ngoại hình, Nhị Khanh được nhắc đến là một cô gái xinh đẹp. Đặc biệt là tính cách nết na được giáo dục bài bản ngay từ khi còn nhỏ: "Nhi Khanh tuy còn nhỏ, nhưng sau khi về nhà ho Phùng, khéo biết cu xủ với ho hàng rất hòa muc và thò̀ chồng rất cung thuận, ngườ ta đều khen là người nội trợ hiền"1. Chung sống với chồng, nhận thấy anh ta ham chơi bời, lêu lổng, Nhị Khanh đã nhiều lần phải khéo léo khuyên can. Lời lẽ của nàng chí tình đạt lý khiến cho anh chồng tuy không nghe theo nhưng vẫn rất kính trọng. Đặc biệt khi Trọng Quỳ phải theo cha đi nhậm chức nơi viễn xứ, chính Nhị Khanh đã phải an ủi: "Nay nghiêm đuờng vì tính nói thăng mà bị người ta ghen ghét, không để ở lại nơ khu yếu, bề ngoài vờ tiến cư đến chốn hùng phiên, bên trong thực dồn đuổi vào chỗ tử địa. Chả lẽ đành để cha ba đào muôn dặm, lam chướng nghìn trùng, hiểm nghèo giũa đám kình nghê, cách trở trong vùng lèo mán, sơm hôm săn sóc, không đõ kẻ thay? Vậy chàng nên chịu khó đi theo. Thiếp dám đâu đem mối khuê tình để lỗi bề hiếu đạo. Mặc dầu cho phấn nhạt huoong phai, hồng rơi tía rụng, xin chàng đùng bận lòng đến chốn huoong khuê". Xem trong lời lẽ, có thể thấy rằng Nhị Khanh là một người dâu hiếu thảo và là một người vợ nết na, chung thủy, suy nghĩ chín chắn và luôn vì người khác. Sau đó, trước sự vần xoay của số phận, ngấp nghé bên bờ của việc bị gả bán cho kẻ khác, nàng Nhị Khanh vẫn một mực hướng về Trọng Quỳ và vững tin người chồng của mình vẫn còn. Đây là lời của nàng Nhị Khanh nói với viên bõ già: "Ta sở dĩ nhịn nhục mà sống là vì nghĩ Phùng lang hãy còn; nếu chàng không còn thì ta đã liều mình chứ quyết không mặc áo xiêm của chồng để đi làm đẹp với nguời khác. Chú có thể vì ta chịu khó lặn lội vào xứ Nghệ hỏi thăm tin tưcc

${ }^{1}$ Cù Hựu, Nguyễn Dữ (1999), Tiễn đăng tân thoại - Truyền kỳ mạn lục, Phạm Tú Châu, Trúc Khê Ngô Văn Triện dịch, Trần Thị Băng Thanh giới thiệu và chỉnh lý, Nxb Văn học, Hà Nội, tr.216. Trích dẫn tác phẩm trong bài viết chúng tôi đều lấy từ đây 
cho ta không?". Niềm tin của nàng đã được đền bù khi viên bõ già đã tìm thấy Trọng Quỳ. Vợ chồng gặp lại, luyến ái yêu đương lại thêm nồng đượm. Tuy thế, Trọng Quỳ ngựa quen đường cũ lại tiếp tục sa vào chơi bời, cờ bạc. Nàng Khanh ra sức khuyên ngăn: "Nhũng người lái buôn phần nhiều là giảo quyệt, đù̀ng nên chơ thân với họ; ban đầu tuy ho thả cho mình được, nhung rồi ho sẽ vét hết của mình cho mà xem". Sinh đã lại không nghe sự khuyên căn chí tính của vợ hiền nên sau đó bi kịch đã xảy ra: nàng bị gá bạc cho tên họ Đỗ. Liệu bề không thể thoát khỏi nên Nhị Khanh đã lựa chọn con đường chết để bảo toàn trinh tiết phẩm giá của người phụ nữ chính chuyên truyền thống cũng đồng thời như một sự cảnh tỉnh đối với Trọng Quỳ. Lựa chọn cái chết không mấy khó khăn với Nhị Khanh, chứng tỏ ở nàng nỗi đau đớn tuyệt vọng đã lên đến đỉnh điểm. Nỗi day dứt cuối cùng của người nữ này chỉ còn là những đứa con thơ mà thôi. Hành động quyết liệt của Nhị Khanh có thể nói là rất đáng khen song suy đến cùng thì cái chết chưa phải đã là một lựa chọn duy nhất. Phải chăng như vậy mà nhà văn Nguyễn Dữ trong phần lời bình đã viết: "Than ôi, nguời con gái có ba đạo theo, theo chồng là một. Nàng Nhị Khanh chết, có quả là đã theo chồng không? Thua rằng không. Đời xua bảo theo là theo chính nghĩa chú không theo tà duc. Chết hợp với nghĩa, có hại gì cho cái đạo theo. Theo nghĩa túc là theo chồng đó". Tất nhiên, chúng ta cũng như nhà văn hoàn toàn có thể chia sẻ với bước cùng cực của nàng lúc đó. Song nếu tìm đường bảo toàn tính mệnh để toan tính cho một cuộc đổi thay nào đó thì có lẽ sẽ ưu việt hơn. Dầu thế, cái chết đã có giá trị cảnh tỉnh to lớn đối với gã Trọng Quỳ bạc nhược. Sự ăn năn hối lỗi khi người vợ đã chết dường như trở thành vô nghĩa, nếu không hướng đến việc nuôi dạy con cái (tất nhiên nội dung này nhà văn không đề cập tới). Không phải ngẫu nhiên mà Nguyễn Dữ đã phải mắng gã này là "tuồng chó lợn" và qua đó gửi một thông điệp về việc rèn luyện nhân cách của đấng trượng phu ở đời: "Muốn tề được nhà, phải trước tự sưa mình lấy chính, khiến cho không thẹn với vơ con, ấy là không thẹn với trời đất".

Sự đền bù cho Nhị Khanh sau khi chết được nhà văn nhấn mạnh ở ba điểm: một là được gặp lại Trọng Quỳ để phân trần một lời trước khi vĩnh viễn tan biến vào mây khói: “... Khoảng cuối canh ba, bỗng nghe thấy tiếng khóc nức nở tù xa rồi gần; khi thấy tiếng khóc chi còn cách mình độ nưa trượng, nhìn kỹ thì ngườ khóc chính là Nhị Khanh..."; hai là nàng được hiển linh, theo chầu tả hữu Đức Bà và ăn lộc tại đền Trưng Vương và ba là có năng lực đoán trước tương lai nên đã khuyên Trọng Quỳ nuôi dạy hai con trai, sau này ứng mộ cho nghĩa quân Lam Sơn của Lê Lợi, làm đến chức Nhập thị nội. Sự đền bù như vậy, thoạt nhìn vẻ như cũng thỏa đáng đối với một con người hội đủ những tính cách, phẩm chất cao quý. Song, cuộc sống dương thế mới là có thật, hữu hình còn thế giới bên kia chỉ là ảo ảnh. Sự đền bù cho Nhị Khanh chỉ mang màu sắc "an ủi cổ tích" còn chung cục, cuộc đời của nàng là cuộc đời bi kịch. Theo dõi toàn bộ diến biến của truyện, Nhị Khanh dường như chưa có được một ngày hạnh phúc. Trong mọi việc, kể từ khi theo làm dâu nhà họ Phùng, mặc dầu nàng là người chủ động song diễn biến cuộc sống lại chưa bao giờ theo như toan tính. Nàng đã gồng lên để sống, để tạo dựng hạnh phúc dù giản đơn nhất nhưng hạnh phúc đã mãi là một tầm với với nàng. Xây dựng mẫu người như nàng Khanh, một mặt, nhà văn thể hiện tiếng nói phê phán, lên án đối với giới nam đã không những không mang lại hạnh phúc cho người nữ mà còn xô đẩy họ vào bi kịch (những kẻ như Trọng Quỳ), mặt khác lên án hiện thực triều chính lúc bấy giờ (những bọn gian thần xiểm nịnh đấy Phùng Lập Ngôn đi viễn xứ khiến cho cha con, chồng vợ phải xa nhau) và cũng đồng thời tác giả thể hiện tiếng nói thông cảm, đồng tình, khẳng định và ngợi ca những phẩm chất cao quý, tốt đẹp của người nữ trong xã hội. Đây chính là phương diện tạo nên nguồn cảm hứng nhân văn trong tập truyện.

\subsubsection{Nhân vật Vũ Nuơng trong "Chuyện người con gái Nam Xương”}

Vũ Nương hay Vũ Thị Thiết, người con gái Nam Xương là một phụ nữ "thuỳ mị nết na" lại thêm có " $t u$ dung tốt đẹp". Có lẽ chỉ với hai phẩm chất này, nếu tạo hóa công bằng cũng có thể hứa hẹn ở nàng một cuộc sống tốt đẹp và hạnh phúc? Khi được gả vào nhà Trương Sinh, nàng thực sự là người con dâu chí hiếu, người vợ mẫu mực và người mẹ hiền từ. Trên ý nghĩa ấy, nàng được coi như báu vật với mẹ con Trương Sinh. Ngay cả với người chồng "ít học" lại "có tính hay ghen, đối với vợ phòng ngừa thái quá" thì nàng vẫn luôn "giữ gìn khuôn phép, không từng lúc nào để vợ chồng phải thất hoà". Con người ấy, phẩm chất ấy đâu phải cứ tìm là có được?

Lấy chồng không được bao lâu thì Trương Sinh phải sung lính, tham gia vào cuộc chiến phi nghĩa giữa các tập đoàn phong kiến lúc bấy giờ. Tiễn chồng tòng quân cũng chỉ một lòng mong mỏi chồng trở về bình an chứ phong hầu, bổng lộc không phải là điều cô quan tâm: "Lang quân đi chuyến này, thiếp chẳng dám mong được đeo ấn hầu, mặc áo gấm trở về quê cũ, chỉ xin ngày về mang theo được hai chũ bình yên, thế là đủ rồi. Chỉ e việc quân khó liệu, thế giặc khôn luòng, rợ man chạy tội, vuoong su uổng công; lòi tâu công lớn phá giăc đã chầy, kỳ hẹn thay quân hóa muộn, khiến thiếp ôm nối quan hoài, me già triền miên lo lắng. Trông mảnh trăng Truờng An, nhanh tay đập áo rét, ngắm liê̂u tàn rủ bóng động nỗi niềm biên ải xa xôi. Giả sủ có muôn hàng thu tín, chỉ e không một tin về". Chồng xa trận, con thì còn nhỏ, mẹ thì già héo, mọi lo toan cho cuộc sống gia đình đặt lên đôi vai của người phụ nữ này. Mẹ chồng già yếu ốm đau vì nhớ con, nàng một mực thuốc thang bái lậy, lại dùng lời ngọt ngào động viên và chia sẻ. Mối quan hệ me chồng - nàng dâu vốn là một mối quan hệ khó điều hoà vậy mà, mẹ chồng cô, trước khi nhắm mắt xuôi tay đã phải ghi nhận công lao và phẩm hạnh của con dâu mình: "- Ngắn dài có số, tuơi héo bởi tròi. Me không phải không muốn đợi chồng con về, mà 
gương cơm cháo. Song tuổi tho có chùng, số trời khó tránh. Đêm tàn chuông đổ, số tận mệnh cùng; một tấm thân tàn, nguy trong sớm tối, không khỏi phải phiền đến con. Chồng con xa xôi, mẹ chết lúc nào, không thể kịp về đền báo được. Sau này trời giúp ngườ lành, ban cho phúc trạch, giống dòng tuơi tốt, con cháu đông đàn, mong ông xanh kia chẳng phụ con cũng nhu con đã chẳng nõ phu $m e$ ". Không có gì thuyết phục bằng lời mẹ chồng ghi công cho con dâu như thế này. Lòng hiếu nghĩa của Vũ Nương quả là hết sức cảm động.

Lo tang ma chu đáo cho mẹ chồng, Vũ Thị Thiết tiếp tục phải đối mặt với bao khó khăn, cơ cực của cuộc sống hàng ngày. Còn gì bơ vơ, côi cút hơn cảnh thân gái một mình nuôi con như nàng. Thương con và nhớ chồng, nàng thường trỏ bóng mình mà nói với con đó là cha nó. Chi tiết này trong câu chuyện có ý nghĩa nhiều mặt. Nó cho thấy nàng luôn tâm niệm về sự gắn bó của mình với chồng, chồng với mình, mình với chồng khác chi như hình với bóng. Chồng xa nhà, nàng đã một mực giữ gìn trinh tiết, bao lời ong tiếng ve nàng bỏ ngoài tai. Trỏ bóng mình cũng đồng thời cũng nói lên tình thương con sâu sắc của nàng. Làm như thế, nàng hy vọng đứa con nàng sẽ luôn cảm thấy có cha nó bên cạnh. Nàng cố gắng để làm một sợi dây nối tình phụ tử giữa chồng và con mình. Nhưng lời nói dối vô tình với con trẻ lại thành nghiệp chướng, buộc nàng vào nỗi oan khuất trời mới có thể thấu tỏ.

Bi kịch của Vũ Nương có thể tạm thời khái quát từ hai phương diện: phương diện xã hội và và phương diện gia đình. Về phương diện xã hội, có một nghịch lí oái oăm là: xung trận, tham gia chinh chiến là trách nhiệm và cũng là sĩ diện của nam nhi đại trượng phu ở đời. Tất nhiên đó phải là cuộc chiến chính nghĩa. Nhưng thực tế lại chỉ ra rằng: dù chính nghĩa hay như ở đây là phi nghĩa thì chiến tranh bao giờ cũng mâu thuẫn với quyền lợi của người phụ nữ. Chiến tranh đồng nghĩa với biệt li cách trở, nỗi nhớ nhung sầu muộn, nỗi lo âu sợ hãi về tính mệnh của chồng mình. Bao người phụ nữ tiễn chồng ra trận và vĩnh viễn không còn có cơ hội đoàn viên. Tác giả Đặng Trần Côn - Đoàn Thị Điểm đã từng diễn ngôn một cách đầy thuyết phục và cảm động về tâm trạng của người chinh phụ khi chồng đi chinh chiến qua Chinh phụ ngâm khúc.

Xét ở một phương diện nào đó sự trở về lành lặn của Trương Sinh là một may mắn lớn đối với Vũ Thị Thiết. Nhưng "tái ông thất mã", ở đời mọi sự may rủi, họa phúc quả khôn lường, nó nằm ngoài ý muốn chủ quan của con người. Sự trở về của Trương Sinh sẽ là cao trào của nỗi bất hạnh, oan khuất của người con gái Nam Xương. Hành động trỏ cái bóng mình mà nói với con là cha nó của nàng đã được đánh giá là tình thương chồng, thương con sâu sắc lại là căn nguyên bất hạnh cho nàng vì con nàng thì quá bé mà gã Trương Sinh, chồng nàng, lại cả ghen. Sau khi đi chinh chiến về, chỉ với một lời của đứa con nhỏ ngây thơ mà anh ta đã nghi oan cho vợ ngoại tình. Hẳn là anh ta đã phải điên lên như một con hổ dữ. Lúc đầu chỉ là mắng mỏ nhiếc móc; sau thì thượng cẳng chân hạ cẳng tay, đánh đuổi vợ ra khỏi nhà. Lạ thay, đến lời can ngăn, bênh vực của hàng xóng láng giềng mà anh ta cũng không hề hả giận để cho vợ thanh minh, giải thích. Để đến khi mọi chuyện đã rồi thì sự ân hận, tiếc nuối cũng còn có ý nghĩa gì nữa đâu. Tất nhiên, chỗ này cũng có điều nên cảm thông cho Trương Sinh. Vừa đi chinh chiến về, quá mệt mỏi, con người ta rất cần một chỗ dựa là gia đình, bên mẹ, bên vợ, bên con. Vậy mà với anh ta thì sao? Vừa về đến nhà thì đã bao khổ đau. Mẹ già đã khuất núi, tình mẫu tử thiêng liêng, là nguồn an ủi lớn vô bờ đối với anh ta không còn nữa (anh ta đã ra thăm mộ mẹ trước tiên). Mẹ mất rồi giờ với anh ta là còn vợ và con trai, niềm hạnh phúc gia đình nhỏ của anh ta. Vậy mà, con từ chối không nhận cha. Hỏi thì nói: “- Khi ông chua về đây, thuờng có một ngườ đàn ông, đêm nào cũng đến. Mẹ đi cũng đi, mẹ ngồi cũng ngồi, nhung chẳng bao giò bế Đản cá". Người Việt Nam có câu "Đi hỏi già về nhà hỏi trê". Ở vào hoàn cảnh đó, sự nghi ngờ và phản ứng của Trương Sinh quả cũng là hợp lí. Và khi tự cởi mối oan cho vợ, anh ta cũng đã tự dằn vặt, đau khổ và tìm mọi cách để đền bù cho vợ. Đó chính là những điều nên cảm thông cho anh ta. Sự nghi ngờ, sự mất bình tĩnh đã xui khiến Trương Sinh đi đến những hành động bạo lực với vợ: từ bạo lực tinh thần (mắng mỏ, nhiếc móc) đến bạo lực hành động (đánh đuổi đi). Hạnh phúc gia đình tan vỡ chính là ở người chồng mù quáng này.

Chi tiết chiếc bóng là một ám ảnh đối với người viết bài. Chiếc bóng - lời nói dối con trẻ của Vũ Thị Thiết đã đưa đến một cái giá quá đắt cho nàng. Lỗi chính từ cô chăng khi mà con người ta ai cũng có một cái hình và một cái bóng luôn luôn đi cạnh nhau, không thể tách rời. Hóa ra, niềm hạnh phúc của con người lại mong manh đến thế. Kẻ thù của ta chính ngay cạnh ta. Kẻ thù ây ai đã lường hết được. Cuộc đời và số phận con người thật ma quái. Chi tiết nghệ thuật này cho thấy, ý nghĩa tu tương của tác phẩm lớn hơn cả nhũng gì mà thời đại đã cấp cho nhà văn.

Còn nữa, ngay cả khi bị chồng ruồng rẫy, đánh và xua đuổi ra khỏi nhà một cách oan ức thì người phụ nữ này vẫn luôn luôn nghĩ cho chồng. Chưa hề thấy một lời kêu ca, trách móc, nói xấu chồng trước người khác. Hãy xem lời cô nói với Phan Lang (người cùng làng) khi họ gặp nhau dưới Long cung: "Tôi bị chồng ruồng rấy, thà già ờ chốn làng mây cung nước, chứ còn mặt mũi nào về gặp mặt chồng!". Lòng người phụ nữ này luôn canh cánh có được ngày đoàn tụ, dù cho sự đoàn tụ ấy chỉ là trong niềm mơ ước, tưởng tượng. Khi Phan Lang hỏi: "Thwa nurơng tủ, tôi trộm nghĩ, nhà cửa của tiên nhân, cây cối thành rùng, phần mộ của tiên nhân, cỏ gai lấp mắt. Nuơng tử dầu không nghĩ đến, nhung còn tiên nhân mong đợi ở nương tư thì sao?". Vũ Nương đã trả lời: "Tôi có lẽ không thể gưi mình ẩn vết ở đây mãi đượ. Ngựa Hồ gầm gió bắc, chim Việt đậu cành nam. Cảm vì nỗi ấy, tôi tất phải tìm về có ngày". Đến khi được trở về trong sự đền bù cổ tích, Vũ Thị Thiết cũng không một lời oán thán trước khi 
vĩnh viễn tan biến vào nỗi quan hoài của nhân gian: "Thiếp cảm ơn đức của Linh Phi, đã thề sông chết cũng không bỏ. Đa tạ tình chàng, thiếp chẳng thể lại về nhân gian được nũa".

Vũ Thị Thiết đã gồng mình lên để sống, để tạo dựng, để sống thật đầy đặn với gia đình vậy mà chính cái gia đình đó đã đẩy nàng đến tới cái chết. Nàng đã vượt qua được bi kịch do xã hội mang tới nhưng không thoát được bi kịch từ phía gia đình. Nàng đã sống theo những khuôn mẫu, những tiêu chuẩn không phải chỉ của chế độ cũ từng đòi hỏi. Vẻ đẹp nhân cách ở người phụ nữ này đạt tới mức lí tưởng mà hẳn là với những đòi hỏi khắt khe nhất, nghiệt ngã đến đâu cũng không thể đòi hỏi hơn ở nàng được nữa. Thế nhưng những "tín đồ ngoan đạo" nhất của những quan niệm ấy lại là những kẻ bất hạnh, đều gặp phải bi kịch. Sống tuân thủ, phục tùng một cách vô điều kiện mà nàng vẫn không có hạnh phúc, thậm chí là nạn nhân đau khổ của thứ lễ giáo ấy.

Trở lên có thể thấy, hai người phụ nữ, hai hoàn cảnh xuất thân khác nhau, một xuất thân danh giá, một xuất thân bình dân; cùng có nhan sắc, cùng đã luôn cố gắng giữ gìn phẩm tiết, rèn luyện nhân vi và sống đúng với những quy định vốn rất khắt khe của lễ giáo truyền thống song họ lại có cùng một số phận là bi kịch. Nhị Khanh thì chủ động hơn so với Vũ Nương luôn tỏ ra bị động. Trong mọi tình huống, Nhị Khanh ít nhiều được tôn trọng hơn (trong nhận thức của Trọng Quỳ) còn Vũ Nương lại bị bạc đãi hơn, thậm chí còn bị ruồng rãy, đánh đập. Tuy thế, việc đem cả vợ ra để gá bạc của Trọng Quỳ quả không thể chấp nhận, so với Trương Sinh - vốn còn có thể lượng tình, cảm thông. Không phải ngẫu nhiên mà Trọng Quỳ bị mắng là "tuồng chó lợn" còn Trương Sinh cũng chỉ bị phê phán "làm người đàn ông, tưởng đìng nên để cho giai nhân oan uổng”. Cả hai người nữ đoan chính có số phận đau thương đã nêu những tấm gương tiết liệt để đã và sẽ mãi lưu lại trong trí nhớ cùng nỗi quan hoài của nhân gian.

\section{Kết luận}

Từ số phận của nàng Nhị Khanh và Vũ Nương - mẫu người nữ đoan chính cho thấy rằng, dù người phụ nữ có rèn luyện Tam tòng, Tứ đức đến đâu, có chấp nhất nghiêm chỉnh và gồng mình lên mà sống theo chuẩn mực của lễ giáo phong kiến đến đâu thì số phận của họ vẫn là số phận của những con người đau khổ, bất hạnh và bi kịch. Phản ánh về cuộc đời và số phận của hai nàng, một ý nghĩa khách quan vượt ra ngoài cái chủ quan của Nguyễn Dữ: lễ giáo phong kiến khô cứng thật là tai hoạ đối với người phụ nữ và càng sống theo những yêu cầu của lễ giáo phong kiến thì cuộc sống của họ, số phận của họ càng nhiều bi kịch. Đó là sự phản ánh trong năng lực nhận thức của nhà văn thời đại bấy giờ bởi nếu nhìn xuyên suốt tập truyện thì ngay cả đến những người phụ nữ phi truyền thống, phá cách như nàng Lệ Nương (Lệ Nuơng truyện) hay nàng Thúy Tiêu (Thúy Tiêu truyện), nàng Nhị Khanh (Mộc miên thu truyện)... thì chung cục số phận của họ cũng tương tự. Đó chính là sự minh chứng cho sự bất lực trên hành trình nỗ lực và khát vọng tìm kiếm lời giải cho số phận, phúc của người nữ ở nhà văn trong bối cảnh xã hội, thời đại lúc bấy giờ. Mệnh danh Nguyễn Dữ như là cha đẻ của chủ nghĩa nhân đạo trong văn học Việt Nam cũng không phải là quá lời (ý của nhà nghiên cứu Nguyễn Đăng $\mathrm{Na}$ ). Còn trong trường hợp này, với người nữ đoan chính, chúng tôi lại có một niềm tin khi thời đại đã đổi thay, họ sẽ là những người xứng đáng và sẽ có được một cuộc sống hạnh phúc vững bền. Đó chính là ý nghĩa giáo dục to lớn cũng như tính thời sự của tác phẩm./.

\section{TÀI LIỆU THAM KHẢO}

1. Cù Hựu - Nguyễn Dữ (1999), Tiễn đăng tân thoại Truyền kỳ mạn lục, Phạm Tú Châu, Trúc Khê Ngô Văn Triện dịch, Trần Thị Băng Thanh giới thiệu và chỉnh lý, Nxb Văn học, Hà Nội;

2. Toàn Huệ Khanh (2004), Nghiên cúu so sánh tiểu thuyết truyền kỳ Hàn Quốc - trung Quốc - Việt Nam thông qua Kim Ngao tân thoại, Tiễn đăng tân thoại, Truyền kỳ mạn lục, Nxb Đại học Quốc gia Hà Nội, Hà Nội;

3. Bùi Duy Tân (1999), "Truyền kỳ mạn lục, một thành tưu của truyện ký văn học viết bằng chũ Hán”, Khảo và luận một số tác gia tác phẩm văn học trung đại Việt Nam, tập 1, Nxb Giáo dục, Hà Nội, tr.372-408;

4. Lê Văn Tấn (2015), "Số phận nguời phu nũ trong Truyền kỳ mạn luc của Nguyễn Dũ: Nghiên cúu truòng hơp Vũ Thị Thiết và Nhị Khanh", Tạp chí Nhân lục Khoa hoc xã họi, Học viện Khoa học xã hội, số 1(20), tr.94-99;

5. Vũ Thanh (2007), "Thể loại truyện kỳ ảo Việt Nam thời trung đại - quá trình nảy sinh và phát triển đến đỉnh điểm”, Văn học Việt Nam thế kỷ X-XIX - Nhũng vấn đề lý luận và lịch sủ, Trần Ngọc Vương chủ biên, Nxb Giáo dục, Hà Nội. 